American Journal of Economics and Business Administration 2 (2): 185-188, 2010

ISSN 1945-5488

(C) 2010 Science Publications

\title{
The Street Vendors of Bangkok: Alternatives to Indoor Retailers at a Time of Economic Crisis
}

\author{
John Walsh \\ School of Management, Shinawatra International University, 16th Floor, \\ Shinawatra Tower III, Viphawadi-Rangsit Road, Bangkok 10900, Thailand
}

\begin{abstract}
Problem statement: During an economic crisis, consumers will use different techniques to make their money go as far as possible: More carefully comparing prices at point of sale locations, bringing out the coins they previously left unused in saving banks, switching to lower cost options and choosing to shop in less convenient locations in order to find discounts. One such option is to use street vendors rather than regular indoor retailers. Street vendors can provide cheaper goods because, in many cases, they do not need to pay for electricity or water bills and their rental costs can be much lower. Further, vendors themselves may be more willing to enter into haggling negotiations and offer cash discounts to well-known or regular customers. However, it would be wrong to assume that all street vendors are the same in terms of character or that they operate according to the same business model. Approach: This is a case study based principally on secondary sources and recapitulating primary research reported previously. Results: Research among street vendors in several locations reveal a wide variety of experiences, ability to provide value added goods and services and intentions and ambitions for the business concerned. While the majority of vendors have quite low levels of ambition, earn minimum wages or less and have little concept of marketing or adding value to products, there are other vendors who have organized their own international supply chains, contract manufactured their own branded goods and franchise stalls throughout the city of Bangkok. In some cases, therefore, street vending should be encouraged because it can offer a route out of the informal economy and into the formal economy for people who might not otherwise be able to achieve regular employment. Vendors also offer, in some cases, good quality alternatives to indoor retailers and help keep prices as a whole down. Conclusion/Recommendations: This case study addressed the question: When should the informal economy be supported and when should it be regulated on the basis that its low standards and semi-legal status damage the economy and society as a whole? The answer is not definitive and sufficient information is provided for readers to determine appropriate answers in different circumstances, which will be informed by individual opinions and principles.
\end{abstract}

Key words: Informal economy, branding, spatial economics, consumer behavior

\section{INTRODUCTION}

The informal sector plays an important role in any developing nation, albeit one that is controversial and often difficult to understand. It includes a very wide range of experiences and degrees of security. Many of the jobs available in the informal sector are illegal in themselves or else have some illegal aspect to them; for example, most people in the sector do not pay taxes or abide by public health ordinances and regulations. This makes them inherently dangerous because of the possibility of arrest by the police or harassment by officials acting corruptly or by organized criminal gangs. At the same time, informal sector workers find it very difficult to obtain public services and to gain access to the kinds of resources and training that would be important in helping people escape from the informal sector into the formal sector. Most governments have the policy goal of encouraging people to move out of the informal sector and into the formal sector for such purposes as broadening the tax base, increasing regulation of the conditions in the labor market and enhancing the ability to plan for the future. Street vending is an important part of the informal sector and one which can occupy a midway point between the official and unofficial economies. Street vending must, by its very nature, be a visible occupation because customers will not buy from someone who cannot be seen-especially in Bangkok, where demands for attention are numerous. Consequently, anyone walking the streets of that city is constantly assailed by appeals to all the senses and 
encouraged to buy food, beverages, clothes, accessories, pirated goods and items of all kinds. As Table 1 shows, there are more than 16,000 registered street vending businesses in the capital-how many unregistered businesses also exist if of course unknown. The majority of the registered businesses are related to food and these cover before stationary and mobile stands. Food-related vending represents the typical vision of what such a business of this sort is like-it is a low value-added, low-profit, low-skilled operation which offers little opportunities for sustainable employment growth without external financial support. Yet these 'old generation' of street vendors are increasingly being accompanied by new generations of vendors, many of whom have education in business subjects and are capable of using techniques and skills learned to improve their businesses sustainably and achieve competitive advantage on a long-term basis.

One of the principal turning points in the emergence of a new generation of street vendors was the 1997 Asian Financial Crisis, together with various aspects of urban development and policy. These issues are explained below.

The 1997 crisis: The 1997 Asian financial crisis began in Thailand with a run on the national currency, the baht, which was defended by the Central Bank. Such a defense was impossible to maintain and, subsequently, structural weaknesses in the Thai economy were exposed and, then, exacerbated by the IMF's program of cuts and market openings as conditions for lending needed money. A large number of factories and other businesses were closed, many needlessly as a result of the IMF's approach, with great loss of jobs. What happened to the unemployed varied according to who tells the tale: On one hand, it is argued that most of the jobless returned to provincial hometowns where relatives, exhibiting characteristic Thai kindness, tended to them and supported them; on the other hand, it is also argued that although many people did return to provincial homes, that then resulted in underemployment and poverty as existing employment opportunities were divided among a suddenly much larger of workers. In any case, research has shown that a substantial number of individuals, among them many former white collar workers, decided to remain in the capital city of Bangkok and put into practice their acquired commercial skills in creating their own street vending businesses. In doing so, they created a sub-set of street vending businesses that may be called 'new generation.' Gathering around urban spaces where emergent supply of foot traffic is evident, such as close to Skytrain and Subway station entrances, the new generation is able to target more upmarket and profitable goods and services-mass transit ticket prices are low in international terms but still high enough to exclude most of the city's population, at least on a regular basis. These vendors represent a means of starting a successful business that may be emulated by those unfortunate individuals who may lose their jobs in the present economic crisis. However, to date, the 2008-9 financial crisis (which is likely to continue beyond the end of the year) has primarily affected people in the manufacturing industry, with factories closing largely as a result of decreased demand for Thai exports. Most such workers are comparatively poorlyeducated and with few resources to start a business outside of the old generation mentality.

However, it is important to note that, in terms of numbers, the great majority of street vendors remain firmly within the low value-added sector, with few prospects or ambitions to improve their situations. This is the most common circumstance: Research both in Bangkok and elsewhere indicated that most street vendors retain very low aspirations for their business.

Spatial changes and urban management: Street vendors in Bangkok are convinced that it is necessary to be as close as possible to potential customers in order to be successful. Bangkok residents tend not to walk very far: It is hot, the pavements are often cluttered, dirty and even hazardous, pollution and heavy traffic also reduce the attractiveness of the prospect of walking. Consequently, vendors are always alive to the changing flows of foot traffic in the city. Once the subway and skytrain systems opened, for example, they represented important changes in the flow of traffic, especially at regular and predictable times during the day. The stations also had an impact on residential patterns as people sought, over the medium to long-term, to move house to somewhere conveniently close to such a station.

Table 1: Registered street vendors in Bangkok

\begin{tabular}{ll}
\hline Items & Total of vendors \\
\hline Noodles & $1,010(6.18 \%)$ \\
Food & $4,333(26.50 \%)$ \\
Regional food (southern and northern) & $1,733(10.60 \%)$ \\
Desserts & $1,283(7.85 \%)$ \\
Beverages & $997(6.10 \%)$ \\
Fresh vegetables and fruit & $2,470(15.03 \%)$ \\
New clothes, bags, hats, shoes & $3,652(22.34 \%)$ \\
Second-hand products and clothes & $2(0.01 \%)$ \\
Telephones, mobile phones and accessories & $27(0.16 \%)$ \\
Lottery & $424(2.58 \%)$ \\
Cosmetics, gift items and accessories & $344(2.10 \%)$ \\
Buddha images and antiques & $74(0.45 \%)$ \\
Total & 16,349 \\
\hline Source: BMA distrit office level figures 2007 &
\end{tabular}

Source: BMA district office level figures, 2007 
Consequently, vendors have done what they can to open their stalls in proximity to these new and very desirable facilities (there is also additional retail space within the stations themselves, which some have sought to explore). This has brought some conflict with the Bangkok Metropolitan Administration (BMA), which is the organization charged with managing the city. In general terms, the BMA would like to clean up the city and create a kind of 'living museum,' in which colorful and longstanding economic activities are restricted to well-regulated sites to which tourists and residents may be directed. These sites would offer electricity and water supplies as well as public health amenities. Money would be recovered from street vendors in registration fees and subscriptions to offset the initial costs. Moving to such sites is resisted by most street vendors on account of the cost of doing so (including the costs of becoming an official part of the taxation system) and because of the comparatively long distance it would put between vendors and potential customers. To date, the BMA's efforts have received mixed results: There are success stories, such as the Bon Marche market in the north of the city, which is aimed primarily at middle and upper class customers who drive and park their cars in the car park provided. The quality of the goods available is generally high but so too are the prices; few bargains are available at this market and there is clearly a limit to the number of such markets that can be successfully accommodated in the city. On the other hand, attempts to clear some of the older and less picturesque markets in central Bangkok have led to violence and resistance. Gangsters have been joined by, it is alleged, off-duty law enforcement and military personnel in attempts to forcibly remove vendors from the spaces they have occupied for a number of years.

On the whole, the spread of large, air-conditioned shopping malls and hypermarkets throughout Bangkok (and much of the rest of the country) has provided an expansion of space into which street vendors have moved in large numbers is perhaps the most evident and important evolution in street vending. Within the air-conditioned malls people can shop at some ease and pay a premium on goods and services for doing so; outside, they can find alternatives at lower costs but with some inconvenience in shopping behavior. Thai consumers largely enjoy the opportunity for greater choice that this provides and the synergy shows a flourishing relationship.

Gender implications: Although Thai society is more tolerant of women working in the public sphere than some others, it is nevertheless true that there are limitations on what kinds of work women can do and still maintain respectability. This is particularly true of urban areas, since these are removed from the traditional division of labor attached to agricultural activities. Few Thai women have had public roles in urban work, which was usually reserved for migrant male workers, notably those from China. As a result, the spread of street vending across different parts of Bangkok and, especially, the up-market versions of street vending, has expanded the space in which can work respectably. When patterns of retailing have changed, in spatial terms, then the places in which women work have also changed.

Additionally, the communal nature of much street vending work and its seasonal or daily nature make it possible for women to combine commercial activities with caring for children or elderly people. For example, a woman whose vending work focuses on catering to a lunch time clientele, can combine this with taking children to school prior to working and then collecting them afterwards. Networking among vendors also offers some opportunities for women, especially, to take care of dependents as well as commercial interests on a group basis. It is also the case, especially among some parts of the low value-added sector, that street vending operations are started by women who have accompanied male migrant workers to the city and who see an opportunity both for some additional income and, also, a means of passing the time. Women in this category will plan to work as long as their male companion or relative is contracted to the work and will then abandon it once it is time to return to the provinces. This is another example of the variation in aspiration in terms of starting a new business and a reminder of the need to take street vendors and their operations on a case-by-case basis.

Marketing: For most street vendors, marketing is a basic process and mostly involves calling out to people as they pass by the stall. Few vendors who are employees have received any training and so they rely upon their instincts as to when to call to a potential customer. The only other form of marketing used is to offer a discount to a regular or important customer, although haggling is possible in some cases, especially for those vendors who own their own business. The ability to get on well with customers is prized among street vendors and their employees. This requires not just friendliness but the ability to determine when a sale is possible and when time would be wasted. Given the problems that street vendors occasionally face, the ability to face up to intimidation and threats is also required and this means a certain toughness of character is also helpful. 
For the new generation of street vendors, this situation is rather different. Some conduct (informal) market research and integrate the results with their own understanding of business and of the nature of their customers. This has led some to create their own brands, using the flexible manufacturing systems available in factories-for-rent in the eastern seaboard region. They will design the brand and use it on a variety of products, including clothes and fashion accessories, taking care not to order too many items to be made until the level of demand is determined. Customers are generally willing to pay a modest premium for a branded item.

Distribution for most street vendors is generally handled through daily visits to markets on the outskirts of Bangkok. Several wholesale markets are held regularly and early morning visits are made to acquire stock for the day: Often, the male members of a family will handle this aspect and the female members the retail aspect. People will visit the markets very early in the morning in order to obtain the more promising types of stock and also to avoid the build up of Bangkok's notorious traffic.

For non-perishable items, there may be some redistribution of items which are not selling well at a particular location. Moving products from one area to another might be accompanied by a change in price, sometimes cheaper but sometimes more expensive. For example, one street vendor has several stalls selling female fashion items. The first stop for these items is at a north Bangkok university campus where a twiceweekly market is organized: Goods which are not sold there may be redirected to the Khaosan road area, where many foreign backpacker tourists congregate. In that case, the prices are generally raised for the foreign customers (although there are some style and size issues to deal with). The same vendor also has a regular space in the very crowded Mah Boon Klom (MBK) Centre in the heart of Bangkok's retail sector but is very careful with stock management in that outlet because of the high price of storing goods out of working hours. This vendor is always concerned with trying to make sure that only that stock which can be quickly moved on is purchased in the first place. Being left with a large amount of unsold stock at the close of business would be a significant problem.

In terms of the marketing mix, while there is some flexibility for smart street vendors to vary the product and the place where operations are conducted, it is clear that price is the variable which is the easiest to manipulate and the one which is most commonly changed. Interestingly, research indicates that Thai consumers are keen to demonstrate that they are good at negotiating price and understand the value of a product: They are, generally, willing to pay more for a higher quality item and also expect to pay less for a lower quality item. What is most important is not to lose face by having to admit that they have overpaid for an item, whether that means admitting the error to a close family member or a chance acquaintance.

From the informal to the formal: Since it is a general policy goal to move people from the informal sector to the formal sector, it is necessary to consider how this may be effected and improved. As small scale entrepreneurs, street vendors face the usual set of restraints that such businesspeople face in planning growth and expansion: Lack of resources, difficulties in obtaining finance and lack of skills and competencies (and the time to acquire them). The Thai government from 2001-6 introduced a number of schemes to enhance the ability of entrepreneurs to upgrade their businesses but more needs to be done to make their services available to street vendors-it is necessary, as De Soto (2000) would argue, to recognize the assets of a street vending business as assets on which leverage may be obtained before vendors would be able to improve their situations. Recently, Muhammad Yunus, the Nobel Prize winner, has announced the opening of a branch of his Grameen Bank associated with the Asian Institute of Technology in Bangkok. Although this project seems likely to be devoted primarily towards agricultural issues, it might prove possible to develop a stream of finance and support for urban vendors.

The ways in which legal and institutional support need to be changed and structured to promote street vendors, if it is decided that they should be supported, will vary from country to country and indeed from region to region within some countries.

\section{CONCLUSION}

As Asian economies increasingly become integrated with the international capitalist system, informal markets will develop where formal markets fail or do not provide income and job opportunities for people. In such cases, street vending is one of the informal market activities that will be pursued. Determining whether such activities offer genuine means by which people can raise themselves out of poverty is an important priority for government and will help decide whether such activities should be encouraged, modified or discouraged.

\section{REFERENCES}

De Soto, H., 2000. The Mystery of Capital. Basic Books, ISBN: 978-0-46501-6143. 